\title{
Stress and life satisfaction among university students-a pilot study
}

\author{
Antonia Paschali ${ }^{*}$, George Tsitsas ${ }^{2}$ \\ From $1^{\text {st }}$ International Congress on Neurobiology and Clinical Psychopharmacology and European \\ Psychiatric Association Conference on Treatment Guidance \\ Thessaloniki, Greece. 19-22 November 2009
}

\section{Background}

Life satisfaction has been described as an overall cognitive assessment of one's quality of life. This assessment is based on how people believe their life should be in relation to how it is. Anxiety has a negative impact on well-being and life satisfaction seems to be highly related with life satisfaction among University students. Studies have supported that lower levels of life satisfaction have been related to high anxiety.

\section{Materials and methods}

The study involved 200 University students, sample taken from the National and Kapodistrian University of Athens and the Xarokopion University (100 1st year and 100 4th year). Subjects were asked to complete the STAI-State \& Trait Inventory and Life Satisfaction Index. The questionnaires were given to students to complete during their Fall and Spring semester studies.

\section{Results}

The mean \pm standard deviation of the "life satisfaction score" was $4.3 \pm 0.5$. Moreover, the majority of participants $(63.4 \%)$ were found to have low "life satisfaction" without any differences between the two sexes. Analysis of STAI showed that students low scores in STATE anxiety scale have high scores in life satisfaction scale whereas high scores have low scores in life satisfaction $(\mathrm{p}=0.005)$. Furthermore Trait Anxiety score analysis revealed non significant results. Treating the life satisfaction score as a continuous variable, it was found that the mean score $(4.2 \pm 0.4)$ of students of the 1st year was statistically significantly lower compared to students of the 4th year $(4.4 \pm 0.6, p=0.005)$. Two-way ANOVA showed that the two-way interaction between the year and students' sex $(\mathrm{p}<0.001)$, state of anxiety $(\mathrm{p}=$ $0.034)$, were statistically significant.

\section{Conclusions}

According to the results of this study it can be suggested that students who have low anxiety scores have more life satisfaction. The fact that significant differences were found for the State condition and not the Trait could be explained by the perception and evaluation of the individual. Determining the relationship between anxiety and life satisfaction inthe university students could assist psychological counseling and guidance.

\section{Author details}

${ }^{1}$ National and Kapodistrian University of Athens, Greece. ${ }^{2}$ Harokopio University, Athens, Greece.

Published: 22 April 2010

\section{References}

1. Anderson SA, Bourland SL, Stanley MA, Snyder A: Parental stress and coping during the leaving home transition. Family Relations 1988, 37:160-165.

2. G Novy DM, Beck JG, Averill PM, Swann AC: Quality of life in older adults with generalized anxiety disorder. Aging and Mental Health 2000, 4:315-323.

3. Cook JM, Black BS, Rabins PV, German P: Life satisfaction and symptoms of mental disorder among older AfHcan American public housing residents. Journal of Clinical Geropsychology 2000, 6:1-14.

4. Deniz ME: The relationships among coping with stress, life satisfaction, decision-making styles and decision self-esteem: An investigation with Turkish university students. Social Behavior and Personality 2006, 34(9):1161-1170.

doi:10.1186/1744-859X-9-S1-S96

Cite this article as: Paschali and Tsitsas: Stress and life satisfaction among university students-a pilot study. Annals of General Psychiatry 2010 9(Suppl 1):S96.

${ }^{1}$ National and Kapodistrian University of Athens, Greece 